\title{
Revisiting Wittgenstein on family resemblance and colour(s)
}

\section{Ma (School of Philosophy, Renmin University of China) \\ and}

J. van Brakel (Higher Institute of Philosophy, University of Leuven)

We argue that all general concepts are family resemblance concepts. These include concepts introduced by ostension, such as colour(s). Concepts of colour and of each of the specific colours are family resemblance concepts, because similarities concerning an open-ended range of colour or of appearance features crop up and disappear. After discussing the notion of "same colour" and Wittgenstein's use of the phrase "our colours," we suggest family resemblance concepts in one tradition can often be extended to family resemblance concepts in another tradition, illustrated by Wittgenstein's use of the words Spiel and "game."

\section{Introduction}

It has been suggested that in the Blue Book Wittgenstein intended that all general concepts be understood in terms of family resemblances of its referents, but not in the Philosophical Investigation. ${ }^{1}$ In this connection Sluga distinguishes between three major classes of concepts. In addition to family resemblance concepts (henceforth: FRconcepts) such as language and game, there are two kinds of general terms according to Sluga: ${ }^{2}$

1. Terms for directly observable characteristics (for example: the concept of green). Such "basic and indefinable terms" have no formal definition and are explained by ostensive definitions.

2. Composite terms such as bachelor. They can be defined in terms of other terms. For example: a bachelor is an unmarried man.

3. "Family resemblance terms, in particular, are neither basic nor composite."

\footnotetext{
${ }^{1}$ See Wittgenstein (1969: 17-20), hereafter referred to as BBB. Perhaps Bambrough (1961: 213) was the first to state that all general concepts are FR-concepts.

${ }^{2}$ See Sluga (2006: 4).
} 
Sluga's use of the words basic and composite with respect to Wittgenstein easily leads to misunderstanding. ${ }^{3}$ Admittedly the phrase "basic term" (which was never used by Wittgenstein) is not the same as the phrase "simple object [Urelement]," which he used in the Notebooks 1914-1916 to dismiss the distinction between simple and complex objects (as found in the Tractatus and with Russell). The later Wittgenstein reiterated in the Philosophical Investigations: ${ }^{4}$

Our difficulty was that we kept on speaking of simple objects and were unable to mention a single one.

We use the word "composite" (and therefore the word "simple") in an enormous number of different and differently related ways.

We suggest that these remarks on simple and complex objects also apply to "basic" terms, concepts, or objects. In the Last Writings on the Philosophy of Psychology, Wittgenstein remarked: "The basic concepts are interwoven so closely with what is most fundamental in our way of living that they are therefore unassailable." ${ }^{5}$ That is to say the basic concepts (and terms) are relative to forms of life. ${ }^{6}$ Furthermore, why couldn't the basic terms be FR-concepts? Why can't a FRconcept be a composite concept? The assumption that at the basic level concepts should be "atomic" and completely determined is a remnant of the ideal language syndrome. ${ }^{7}$

In this paper, we shall argue that, with some possible exceptions in theoretical science, all general concepts (including ostensive and composite concepts) are family resemblance concepts. Wittgenstein's "the word must have a family of meanings"

${ }^{3}$ Even though he cautions: "as long as we attach not too much philosophical weight to the word "basic." We can say, in any case, with some confidence that basic terms have no formal definitions and are instead explained by ostension" (Sluga 2006: 3).

${ }^{4}$ Wittgenstein (1979: 68), henceforth referred to as $N B$, Wittgenstein (2009a, §47), henceforth referred to as $P I$.

${ }^{5}$ Wittgenstein (1992: 43f); henceforth referred to as LWPP II.

${ }^{6} \mathrm{Cf}$. "how some words are used will seem simple, lapidary, and basic to us" (Wittgenstein 1990, §287); henceforth referred to as LWPP I.

${ }^{7}$ Frege (1892) specified that an ideal language should be objective (eliminating individual and poetic aspects), exact (each expression has exactly one reference and one sense), structured or compositional (the reference and sense of each expression can be "calculated" from the reference and sense of its constituting parts), and that each sentence is either true or false. 
should be understood to apply to all general words. ${ }^{8}$ The family includes not only the present meanings, but also the historical evolvement of language games, as well as FRrelations with FR-concepts from other traditions.

Our broader aim is not to present a new theory of meaning or of universals, but to investigate the working hypothesis that for interpretation across languages to be possible, it is necessary to assume that all concepts in use involved in the relevant languages are FR-concepts. Interpretation across traditions is only possible provided it is assumed that there are family resemblances between a considerable FR-concepts from different traditions. Concepts from the other tradition can also be learnt in various ways from scratch (for example, by guessing right the intention of ostensive definitions), but this is only possible against the background of a host of already extended FR-concepts of the interpreter. We have addressed this intercultural issue in another paper (van Brakel and Ma 2015). Here we critically discuss in some detail Wittgenstein's sayings concerning explanation by means of colour samples and the restriction of this practice to "our" colour concepts.

Sluga gives three reasons why not all concepts are FR-concepts: ${ }^{9}$

1. Because there are terms capable of being defined.

2. The overlapping and criss-crossing marks are not FR-concepts, because this would lead to an infinite regress. Presumably the regress would be stopped by "basic and indefinable terms" introduced by ostension.

3. Wittgenstein's idea of family resemblance conflates kinship vocabulary (and other kinds of appropriate causal connection) and resemblance vocabulary.

In the following three sections, we present our objections to each of Sluga's three points. In addition we argue that a FR-concept should not be associated with a core paradigm or most salient example. Subsequently, we briefly compare the German and English text of the Philosophical Investigations. Then we address colour-related language games in other traditions and argue that Wittgenstein's reference to "our" colour concepts has to be understood as Wittgenstein's own understanding of colour concepts, placing himself in the tradition of Goethe and Ewald Hering.

\footnotetext{
${ }^{8} \mathrm{PI}, \S 77$.

${ }^{9}$ See Sluga $(2006: 4,14)$.
} 


\section{Wittgenstein's notion of family resemblance}

Different uses of the word game show family resemblances. One "can see how similarities crop up and disappear." ${ }^{10}$ One does not explain such words as game and language by giving analytic definitions, but by giving examples. To emphasize that there is not a particular similarity that runs through all uses of a word such as game, Wittgenstein invokes the image of spinning a thread. "We twist fibre on fibre. And the strength of the thread does not reside in the fact that some one fibre runs through its whole length, but in the overlapping of many fibres." 11

Wittgenstein used the German words Ähnlichkeit and Verwandtschaft (or verwandt) to indicate different kind of relations: ${ }^{12}$

Don't say: "They must have something in common, or they would not be called 'games'، — but look and see whether there is anything common to all. - For if you look at them, you won't see something that is common to all, but similarities [Ähnlichkeiten], affinities [Verwandtschaften], and a whole series of them at that.

Both Ähnlichkeiten and Verwandtschaften are relationships, ${ }^{13}$ but Wittgenstein wants to emphasise that games (and FR-concepts in general) are related in many different ways. Elsewhere he writes: “Don't look only for similarities [Ähnlichkeiten] in order to justify a concept, but also for connections [Zusammenhängen]." ${ }^{14}$ Connections form a third kind of relation. Language events are connected to one another innumerable ways; "there are many different kinds of affinity between them."15 There is a "family of structures more or less akin to one another." 16 Another word that

\footnotetext{
${ }^{10} P I, \S 66$.

${ }^{11}$ Ibid. $\$ 67$.

${ }^{12}$ Ibid. $\S 66$.

${ }^{13}$ In the earlier PI editions, Verwandtschaft was translated as relationship. There are four editions of the Philosophical Investigations in English. We cite from the fourth edition (translation by Hacker and Schulte, on the basis of Anscombe's version).

${ }^{14}$ Wittgenstein (1980, vol. I, §923), henceforth referred to as RPP I and RPP II.

${ }^{15} P I, \S 65$. The original text is: "mit einander in vielen verschiedenen Weisen verwandt."

${ }^{16}$ Ibid., §108. The original text is: "die Familie mehr oder weniger mit einander verwandter Gebilde."
} 
he used is Zwischengliedern (connecting links). One has to look for intermediate cases in order to connect rather dissimilar games. ${ }^{17}$

Sluga argues that most terms can be approached as either kinship terms or resemblance terms. He criticises Wittgenstein for not clearly separating the notions of kinship and similarity. We suggest that, in not doing so, Wittgenstein wants to emphasise that his notion of family resemblance involves a variety of similarity relations between the referents of a FR-concept. ${ }^{18}$

An often overlooked aspect of Wittgenstein's FR-notion is articulated in the following passage: "We see a complicated network of similarities overlapping and criss-crossing: similarities in the large and in the small." ${ }^{19}$ In our opinion, similarities in the small refer to prima facie similarities between the referents of FR-concepts. Similarities in the large refer to similar ways of fitting in the embedding forms of life, while similarities in the large would prevent extending the affinity family via irrelevant superficial similarities. FR-concepts are holistically related to other FR-concepts. If we consider a FR-concept as a pattern in the weave of language, then we can cite Wittgenstein saying: "And the pattern in the weave is interwoven with many others." 20

Gert thus defines: "Family resemblances are those salient resemblances which are fairly common to, or distinctive of, the members of a kind, and which we often use to identify members of that kind." ${ }_{21}$ But as the highlighted words show, this definition assumes that one has already known what is salient and distinctive of each kind.

Glock defines the English word game as "rule-guided activity with fixed objectives that are of little or no importance to the participants outside the context of the game," and he adds: "It could be claimed that such a definition does not merely sharpen our concept through a stipulation, a possibility Wittgenstein concedes (PI 69), but captures how we already use 'game'." 22 However, even if philosophers or linguists find a definition of the English word "game" that fits current usage, it still remains

\footnotetext{
${ }^{17}$ Ibid., §122 and Wittgenstein (1993, 133).

${ }^{18} \mathrm{Cf}$. "We use the word 'similar' in a huge family of cases" (BBB: 133).

${ }^{19} \mathrm{PI}, \S 66$.

${ }^{20} R P P$ II, §673; cf. Wittgenstein (1981, §569), hereafter referred to as $Z$.

${ }^{21}$ Gert (1995: 183; emphasis added).

${ }^{22}$ Glock (1996: 121).
} 
open how the future use of this word will develop. ${ }^{23}$ Exceptions can always be found or imagined.

Wittgenstein explicitly denies the validity of disjunctive definitions. Disjunction cannot capture the openness of FR-concepts, whereas disjuncts are themselves FRconcepts as well. When the present use of the word "game" is described as: "either A or $\mathrm{B}$ or $\mathrm{C}$ or ...", it does not tell us anything about the future use of the word. Moreover, it assumes that A, B, C, etc. have precise meanings. ${ }^{24}$ There is no way to regiment future use of FR-concepts by rules. Pelczar proposes that we use the notion of "precedent-setting improvisations" to characterize the openness of FR-concepts. Open practices, such as common law, jazz, conversations are characteristic of semantic openness towards the future, including gradual semantic drift (allows gradual and hardly noticeable addition of new content), ambiguity, vagueness, topicality (variable content depending on the subject matter), layered meanings. ${ }^{25}$ The concepts of family resemblance, open-endedness toward future use, and vagueness are sometimes differentiated, but we include the latter two in our notion of FR-concept. Using concepts involves (Wittgensteinian) rule-following. As von Savigny remarks (1994: 114): "Words for general concepts are not used according to criteria, the use of language is not fixed towards the future and, as to the present, is not generally decidable on the basis of the known contents of a rule."

\section{Prototype theories and the salience of red}

Since its inception by Rosch, the concept of prototype has made an enormous impact in cognitive science, in particular when combined with the notion of basic level

\footnotetext{
${ }^{23}$ Rowe (1992: 13) attempts to separate games from performances and ceremonies and suggests the following definition of game: "An abstract object (either a sequence or a goal) which is designed to have no instrumental value; the realization or pursuit of which is intended to be of absorbing interest to participants or spectators." But why cannot there be games that would have instrumental value?

${ }^{24}$ Wittgenstein uses the image of a thread with overlapping fibres to explicitly dismiss attempts at disjunctive definitions. Even if one has a complete and exact description of the (overlapping) fibres up to a certain point, it does not tell us anything about future overlappings and where a new fibre starts, etc.

${ }^{25}$ Pelczar (2000: 505).
} 
category. ${ }^{26}$ Prototypical basic level categories are functionally, epistemologically, and linguistically primary or salient. They are the categories first learnt by children and most likely to be shared by people of different backgrounds or cultures.

Rosch came to the idea of her prototype theory by confronting the dominant "classical" idea of concepts as defined by necessary and sufficient conditions with Wittgenstein's remarks concerning family resemblance. However, it is wrong to see prototype theory as an outgrowth of Wittgenstein's notion of family resemblance. The crucial difference is that an FR-concept has no central core or essence, whereas the prototype is the core of a graded category. Prototype concepts typically have blurred boundaries, but the prototypical core is fixed. ${ }^{27}$

The "prototype" of a prototypical concept has been considered to correspond to salient features of the world out there, to psychological essences, to mental representations, to neurophysiologically grounded categories, or to concepts in some abstract Platonic realm. No matter which level one investigates, one would find the "same" prototype. However, both the classical and prototype theory approach to concepts are congeners of the ideal language assumption, illustrating what Wittgenstein called "craving for generality." ${ }^{28}$ Such questions as the following can be put to prototype theory:

1. How fixed is the core of the prototype concept? Why could not part of the periphery take the place of the centre at other times or for other communities?

2. How many basic situations are there? Perhaps the number and kind of basic objects and events, the number and type of basic words or sentences, and how borders

\footnotetext{
${ }^{26}$ Rosch views made immediate impact in the 1970s. For the alleged connection with Wittgenstein, see Rosch and Mervis (1975). Psychologists often use the word category where philosophers would use the word concept.

${ }^{27}$ Occasionally Wittgenstein uses terminology that could be taken to support prototype theory. In the English translation of $P I$ the word prototype (of non-satisfaction) occurs once, but translates Urbild (PI, §439). He often uses the word paradigm, but in the sense of example or sample. For example $(Z, \S 420)$ : "It looks red to me."--"And what is red like?"--"Like this." Here the right paradigm must be pointed to.” Cf. Wittgenstein (1978, part I, §105). A paradigm is chosen (Wittgenstein 1977, §III.259), hereafter referred to as $R C$.

${ }^{28}$ Among other things the tendency "to look for something in common to all the entities we commonly subsume under a general term" (BBB: 17).
} 
around basic situations are drawn, depend on the language and situation in which the question is being asked.

Prototype theory as presented by Rosch assumes that a prototypical concept is salient across humanity. In this respect it is instructive to compare the views of Wittgenstein and Quine (although the latter doesn't use the word prototype; instead he speaks of salience). Quine presents the following argument: ${ }^{29}$

Let us imagine a certain response reinforced in the presence of a red ball and penalised in the presence of a yellow rose. A red rose, then, will perhaps not elicit the response, given its favourable colour but unfavourable shape. But if the response was reinforced also in the presence of a red shawl, the red rose will elicit it.

Why would being shown a red ball and a red shawl entail that the red rose requires a positive response? To respond positively to the red rose would be wrong, were it more salient to group ball and shawl together (being "big things" compared with roses). How can the learner know it is penalised for responding to the yellow rose because of its colour? To respond positively to the red rose after having been penalised in the presence of a yellow rose, would also be wrong if colours of items like flowers were seen as different from those of man-made products. In addition, both roses may glisten or have a highly saturated colour, while the shawl and ball are dull. And so on.

Quine would not agree with this reasoning because, according to him, perceiving red is "salient." 30 His view of the relation between perceptual similarity, salience, innateness, and language can be summarised as follows: ${ }^{31}$

Perceptual similarity is subjective in the sense of pertaining only to the single percipient's global stimuli, but objectively testable by reinforcement and extinction of responses. It is in part innate since all learning depends on it.

In terms of objective tests, salience is derivative from perceptual similarity. Parts of two global stimuli are salient if they make for

\footnotetext{
${ }^{29}$ Quine (1974: 18).

30 "Salience expedites the learning of observation words exceedingly. ... Conditions of salience [are] focal position, motion, brightness, boundary contrast, gaudy colour" (Quine 1974: 44, 26). "Color is king in our innate quality space" (1969: 49).

${ }^{31}$ Quine, personal communication 8 June, 1993 to J. van Brakel. Cf. Quine (1974: 17-28, 4344; 1996).
} 
perceptual similarity despite disparity of other parts. Intuitively, on the other hand, salience is what makes for perceptual similarity.

Language and ethnicity eventually intrude and modify perceptual similarity and salience.

Quine assumes that a universal feature of innate sensory capabilities is shared among humans. This guarantees that red is naturally salient. ${ }^{32} \mathrm{We}$ suggest that Wittgenstein would not agree with Quine. For Wittgenstein, all "normal" human beings have (roughly) the same (supposedly innate) discriminatory capacities, but this is not the same as what Quine calls (following Carnap's Aufbau der Welt) "innate similarity spaces." ${ }_{33}$ The (shared) discriminatory capacities allow for an indeterminate vast range of possible orderings of the domain of appearance. Quine assumes that these shared discriminatory capacities are sometimes already conceptually structured in a unique way, especially so for basic level concepts such as basic colours. As Wittgenstein's says in several places, the discourse concerning ostensive definitions of colour and colours does not have universal application. It only applies to "our concepts" (see below).

If one is impressed by Quine's reasoning, one isn't taken seriously Wittgenstein's dictum "an ostensive definition can be variously interpreted in any case." 34 Ostensive definitions are underdetermined unless the context has already fixed what kind of thing is pointed at. Furthermore, to know what kind of thing it is, for example an animal or a colour, one has to draw on other FR-concepts and share a form of life with the teacher. Wittgenstein writes: ${ }^{35}$

If I know that someone means to explain a colour-word to me the ostensive definition "That is called 'sepia' " will help me to understand the word.... One has already to know (or be able to do) something in order to be capable of asking a thing's name. But what does one have to know?

\footnotetext{
${ }^{32}$ The shared capacity of recognising saliences is derived from the evolutionary history of humans (Quine 1974: 19; 1996: 160-161).

${ }^{33}$ Quine (1969: 49; 1974: 19).

${ }^{34} P I, \S 28$; cf. §73) “Any definition can be misunderstood” (Wittgenstein 1974, §89), hereafter referred to as $P G$. Cf. $P I, \S 71 ; P I$, marginal note to $\S 29 ; P G: 439$. An explanation is never final, but it is in order if it fulfils its role under normal circumstances (cf. $P I, \S 87$ ).

${ }^{35} P I, \S 30$.
} 
Below we will answer to this question: One must already have a vague idea of the structure of colour space and how to separate it from other appearance features.

Intuitions concerning basic terms having panhuman definitions for words available in all human languages may have been motivated by the overuse of "red" as the prototypical notion introduced by ostensive definition. ${ }^{36}$ For example, Baker and Hacker not only discuss the "alternatives": 37 "This is red," "This colour is called 'red," "This is red, and so is anything similar to this (in respect of colour)." They add prototype terminology such as: "clearly exemplifying the colour red"; "it must be clearly red, not a borderline case"; "overlapping central cases linked in various complex and often tenuous ways with large numbers of different cases" (emphasis added). Wittgenstein was (of course) aware of the tendency to essentialise statements about red: 38

Mostly one [thinks], "Red is a pure colour" is a proposition about the 'essence' of red, time doesn't come into it; one cannot imagine that this colour might not be simple.

We think it is highly unrealistic to use red as the prototypical colour to explain the use of samples in the explanation of words. One would expect "This is red," to be part of showing a whole range of red shades. At some point the teacher might add: "This is also red," pointing to a sample of burgundy red. After a further while: "And this is pure red, the best example or most salient red, which psychologists have defined as 'red' without any trace of either yellow or blue," but this is already bordering on teaching science. As to the phrase "This colour is called ...", how can we know what a colour is, if we don't know what red is? How can we learn/explain what a game is if we don't already know a few games? ${ }^{39}$ Surely one first learns to use words such as red and green and only later one learns the use of the word colour: Red, green, etc. are colours.

\footnotetext{
${ }^{36}$ For example, allegedly, the cognitive and linguistic universal RED is labelled "red" in English, rouge in French, krasnii in Russian, hong in Chinese, tlakwa in Kwakw'ala, and so on, in all human languages.

${ }^{37}$ Citing Baker and Hacker (1980: 96, 104, 93, 111, 99, 51) respectively. The overuse of "red" as example reminds one of Wittgenstein's advice: “A main cause of philosophical disease--a one-sided diet: one nourishes one's thinking with only one kind of example" (PI, §593).

${ }^{38}$ RPP I, $\$ 622$.

${ }^{39}$ Cf. PI, $\$ 69$.
} 


\section{Stipulation of concepts}

Underlying the ideal language project is the assumption that precise meanings are possible and the ideal to strive for. The notion of precise meanings makes no sense for natural languages such as Chinese and English, including philosophical language. For example, one might think that the word "bachelor" has a precise meaning, namely "unmarried man." ${ }^{, 40}$ Although one might stipulate the meaning of bachelor in such a way, a precise meaning of "unmarried" and "man" still has to be given. And one has to accept that the Pope is a bachelor. It is possible to propose a definition specifying necessary and sufficient conditions for the use of a word, but one cannot give necessary and sufficient conditions for the use of all the words that are used in the definition. This is a variant of the problem of complete description. ${ }^{41}$ It is impossible to give the necessary and sufficient conditions for the knowledge or application of a concept or a rule, for the style of a work of art, for the occurrence of an event, and so on. Stipulation aims to make a concept more precise, but this can be done only for a particular application; not for every purpose. ${ }^{42}$ As Wittgenstein remarks: ${ }^{43}$

Can you say where the boundaries are? No. You can draw some; for there aren't any drawn yet. ... To repeat, we can draw a boundary-for a special purpose.

Pelczar suggests Wittgenstein would allow for "rigidly limited concepts" and assumes that "prokaryote" has a "strict definition." 44 However, according to a recent

\footnotetext{
${ }^{40}$ For example, Sluga (2006: 3-4) and Forster (2010: 68), and many others.

${ }^{41} \mathrm{Cf}$. "the very ideas of a complete expression and of a signifier that would cover exactly the signified are both inconsistent" (Merleau-Ponty 1973: 29).

${ }^{42}$ It has sometimes been argued that "number" is not a FR-concept. Wittgenstein emphatically states that it is. "I can give the concept of number rigid boundaries in this way, that is, use the word 'number' for a rigidly bounded concept, but I can also use it so that the extension of the concept is not closed by a boundary" $(P I, \S 68)$.

${ }^{43} P I, \S \S 68-69 ;$ cf. PI, $\$ 71 ; P G, \S 75$.

${ }^{44}$ Pelczar (2000: 498) misreads PI, §68. Wittgenstein is saying, "I can give the concept 'number' rigid limits" (emphasis in German original). Sluga also remarks that Wittgenstein never said there couldn't be strictly defined concepts.
} 
publication in the philosophy of biology, the prokaryote species concept does not exist, not even as a family resemblance concept. ${ }^{45}$

In passing it may be noted that stipulation is involved in an ostensive definition of a unique sample such as the standard metre in Paris, which is used as standard of comparison. All metre sticks should be equal in length (as far as technology allows), presupposing a measuring practice of length based on (indirect) comparison with the standard. ${ }^{46}$ We won't argue that "one metre" is a FR-concept. Cases of stipulating the name of particular objects (a mountain, a person, the standard metre) do not enter the discussion of family resemblance, unless a description is involved that uses FRconcepts (which is often the case in order to specify relevant features of the context).

We conclude that concepts stipulated by conventional definitions are FR-concepts at one remove. At any moment, new events may suggest to understand a stipulated concept differently, by exploiting the FR-features of the concepts that define the stipulated concept. Stipulated concepts can always be "opened" by raising questions concerning the meaning of the FR-concepts used in the stipulation.

\section{Family resemblance and ostensive definitions}

There seems to be consensus in the secondary literature on Wittgenstein that words introduced by ostension are not FR-concepts. In this section we will argue that socalled ostensive concepts should also be considered FR-concepts. We don't deny important differences between a FR-concept such as colour (or green) on the one hand and a FR-concept such as game or chess on the other. However, if we compare the two

${ }^{45}$ Ereshefsky (2010). Prokaryotes may be roughly defined as usually unicellular organisms whose cell(s) lack a membrane-bound nucleus. There seems to be no easy connection between features of cellular organization and biological classification of species.

${ }^{46}$ To avoid the need to (fallibly) give a precise description of the standard, there has been a development towards definition in terms of physical magnitudes that are assumed to be absolutely constant (assuming that physical laws never change). In Wittgenstein's times the metre was stipulated to be "the distance between the two engraved lines on a bar of platinumiridium alloy kept at zero degrees centigrade in a vault at the International Bureau of Weights and Measures at Sèvres, near Paris." The current definition is: "1,650,763.73 times the wavelength of the orange-red radiation emitted by Krypton- 86 atoms kept in a vacuum and excited at the triple point of nitrogen, which radiation is emitted when Krypton-86 electrons excited to the $5 d_{5}$ energy level fall back to the $2 p_{10}$ level." 
types there are many similarities and enough reason to consider colour (s) FR-concepts. First we present a list of similarities between the "game" and "colour" paradigm, taking a typical characterization of the family resemblance of games as a point of reference.

Like games, colours (green, magenta, ...) and colour shades (of yellow, of sepia, ...) are connected by a complicated network of similarities, a large number of relationships. For example, (shades of) colours can be (dis)similar in degree of saturation or metallic appearance. Similarities and differences with respect to the dimension or parameter degree of saturation crop up and disappear. The same applies to all other dimensions of colour, and Wittgenstein seems to agree (see next section).

There are no sharp boundaries (unless we stipulate them) of what is (still) a game or (still) a colour. Technological construction of as yet non-existing colours is possible. New colours might show up in new environments (e.g. for humans in outer space) or esoteric experimental conditions. New games can be invented.

Though indefinable, ostensive concepts can still be explained and learnt, like other FR-concepts. For each one can say: teaching by example/sample, points beyond them, employing examples/samples in a particular way. Wittgenstein writes: ${ }^{47}$ "Our learning has the form 'that is a violet', 'that is a table'." The role of pointing to a violet or to a table is the same. Both a violet and a table can be considered either a sample or an example.

Also colour can be used to support Wittgenstein's concern to undermine that "there must be something in common"; for example, the widespread but mistaken belief that colours can be defined in terms of wavelength of light.

Chess is defined by rules, but the rules can be different (as in Indian chess). The same is true for the rules of colour space (colour grammar). Instead of games a community could have sports and playing (and no games). Instead of colour a community could have brightness and ripeness (but no colour) or degrees of brightness and dry/wetness (but no colour).

One needs to distinguish between the family resemblance of colours (under the general concept of "colour") and the family resemblance of different distinguishable samples of a particular colour, for example shades of sepia or green. Colour is a FRconcept. Different colours are FR-concepts. Concerning the former Wittgenstein gives

\footnotetext{
${ }^{47}$ Wittgenstein $(1975, \S 450)$
} 
reasons why "colour" is a FR-concept (and therefore concepts of different colours as well): ${ }^{48}$

Our colour concepts sometimes relate to substances (Snow [sic] is white), sometimes to surfaces (this table is brown), sometimes to the illumination (in the reddish evening light), sometimes to transparent bodies. And isn't there also an application to a place in the visual field, logically independent of a spatial context?

In many places he stresses the peculiarities of the appearance of transparent media. ${ }^{49}$ His remarks "correspond" to the scientific observation that dimensions of surface colours are not the same as the dimensions of coloured lights, volume colours, film colours, or colours "caused" by rare physical processes. Recognising that colour is a FR-concept explains apparent anomalies such as: "The white paper gets its lightness from the blue sky." ${ }^{50}$ That is to say: the blue of the sky is lighter than the white of the paper, although "normally" white is always lighter than blue.

What about the difference of a sample of green and an example of a game? First note that in colloquial English "showing a number of typical language games" could be paraphrased by saying "showing a representative sample of language games. Further remember that "sample" is also a FR-concept and a distinction between sample and example can only be made by stipulation. Unfortunately, both in the Philosophical Investigations and in the secondary literature no clear distinction is made between the use of the word sample for unique samples, which serve as a standard of comparison, and samples that are representative of a set of samples. We already mentioned the length of the standard metre as a stipulated sample. The standard metre is the defining paradigm (example, sample) relative to which copies are compared. Wittgenstein writes: $:^{51}$

Let us imagine samples of colour being preserved in Paris like the standard metre. We define: "sepia" means the colour of the standard sepia which is there kept hermetically sealed. Then it will make no sense to say of this sample either that it is of this colour or that it is not.

\footnotetext{
${ }^{48} R C$ III, $\S 255$.

${ }^{49}$ For example, $R C$ III, $\$ 239$.

${ }^{50} R C$ I, $\S 2$ or III, $\S 132$.

${ }^{51} P I, \S 50$.
} 
This is a rather odd analogy. The analogy with the standard metre suggests that only one sample of sepia is kept in Paris. It could be the standard of comparison for the colour of old photographs. ${ }^{52}$ But the one sample cannot represent all of sepia. There is no rule (practice) of comparing various sepias with the standard kept in Paris (as there is for the standard metre and the practice of measuring length). In current practice sepia will be defined in terms of its location in colour space. That is to say, a better analogy might be: The colour solid (see next section) functions like the standard metre.

\section{"Same colour" and its dimensions}

Wittgenstein and most colour scientist, technologists, and artists consider colour to have three dimensions; ${ }^{33}$ hence each particular colour can be defined in terms of the values of these three variables. In one place Wittgenstein specifies the three dimensions as "degree of saturation, hue and intensity of light" and in another place as "saturation, hue, and brightness." ${ }_{54}$ Usually lightness and brightness refer to object colours and colour of light sources respectively. ${ }^{55}$ Hue is not a common sense notion, but primarily associated with splitting the spectrum. The (monochromatic) hues in the spectrum are only a very small part of the extension of the FR-concept colour, although strictly speaking there are millions of them (determined by discrimination capacities of humans and variations of viewing conditions). 56

Three dimensions are used in many colour models, for example in the double cone (with four primaries) Wittgenstein draws at one time, ${ }^{57}$ or the irregular Munsell colour

${ }^{52}$ Sepia is a brownish-gray to dark olive-brown colour; a reddish-brown colour associated particularly with early monochrome photographs; originally a brown melanin-containing pigment from the ink of cuttlefishes.

${ }^{53}$ These three dimensions should not be confused with the three or four primaries mentioned later and the trichromacy of the human retina.

${ }^{54} P R, \S 66$ and $Z, \S 269$ respectively. Intensity (of light) is a physical magnitude. Lightness and brightness are psychophysical variables.

${ }^{55}$ Wittgenstein doesn't seem to differentiate lightness and brightness, using the words interchangeably.

${ }^{56}$ Probably still under the influence of Newton, colours seen in the spectrum are said to be red, orange, yellow, green, cyan, blue and violet. Non-spectral colours (a range of purples or magenta) are added to obtain a hue scale such as a colour circle.

${ }^{57} P R, \S 221$. 
solid (with five primaries), which claims the "distance" between colour shades to be measured in terms of just noticeable differences. ${ }^{58}$ Wittgenstein is well aware that colours defined in terms of three dimensions leave many features of appearance or colour out of consideration. He mentions the following non-Munsell features of colours a number of times. ${ }^{59}$

Mightn't shiny black and matt black have different colour-names?

This suggests that shiny black and matt black are different colours (a difference not covered by the three dimensions of hue, saturation, and light/brightness). ${ }^{60}$ Further: ${ }^{61}$

It is easy to see that not all colour concepts are logically of the same sort.

We speak of the 'colour of gold' and do not mean yellow. "Goldcoloured" is the property of a surface that shines or glitters.

There is the glow of red-hot and of white-hot.

It is only to be expected that we will find adjectives (as, for example, "iridescent") which are colour characteristics of an extended area or of a small expanse in a particular surrounding "shimmering", "glittering", "gleaming", "luminous").62

If we consider other possible life forms we may be tempted to acknowledge more possible dimensions of colour or may prefer to say that in the other tradition there is no colour concept, but a range of appearance concepts that show family resemblances

${ }^{58}$ The Munsell system uses five primaries, including purple in order to cover the large "difference" between red (or pink) and blue. There are many different models of colour space. We will use the well-known Munsell system as point of reference.

${ }^{59} R C$ III, $\S 152$.

${ }^{60} \mathrm{Cf} . N B: 61 ; R C$ I, $\S 50$ and III, $\S 107$.

${ }^{61} R C$ I, $\S 54$ (or III, §241); I, §33; I, §34 (cf. II, §17); and III, §66 respectively. See on silver and gold colour also $R C$ III, $\S \S 51,100$.

${ }^{62}$ In Sanskrit, there are more than ten words allegedly to be rendered as red in English (not including the many words for reddish-brown, and so on); the Rig Veda (ca $1500 \mathrm{BCE}$ ) is full of them (Hopkins 1883). Whole ranges of intricate semantic networks exist that touch only tangentially on what in Western languages might be described as chromatic appearance, but are better approached via extension of concepts such as brilliance, transparency, brightly illuminated, shiny, glittering, luminous aspects associated with the sunset and landscapes, and so on. 
with "our" colour concepts.

Let us consider a concrete example of a language game that cannot be captured by a three-dimensional colour space model. ${ }^{63}$ In the Karam language, what is according to the Munsell system "the same colour," may be referred to by two or more different words, depending on circumstances. For example, it is reported that leaf surfaces with the same Munsell code (5GY/4/4), specifying the three dimensions of hue, saturation, and lightness, might be identified as "dark," "yellow," or "succulent green," depending on the context of comparison with other leaves, stems or other vegetal parts. ${ }^{64}$ Of course the glosses "dark," "yellow," and "succulent green" are not literal translations; they give a hint of what is being referred to, assuming that one is interested in what is conventionally called colour in English. There is no Karam word that just means "standard" green. If we would accept the three Karam words as an extension of our colour grammar, we would need more dimensions than the three of the Munsell system. This "natural” example can be contrasted with one of Wittgenstein's artificial language games: ${ }^{65}$

\begin{abstract}
And what about people who only had colour-shape concepts? Should I say of them that they do not see that a green leaf and a green table-when I show them these things--have the same colour or have something in common? What if it had never 'occurred to them' to compare differently shaped objects of the same colour with one another? Due to their particular background, this comparison was of no importance to them, or had importance only in very exceptional cases, so that no linguistic tool was developed.
\end{abstract}

\footnotetext{
${ }^{63}$ The following language games bearing similarity to "our" colours are drawn from linguistic anthropology. Following academic standards a reference to the source of the "data" is given, but they may as well be considered artificial language games. Naturalness and inventedness (also referred to as the duality real/imaginary or hypothetical/constructed) should be viewed as two inseparable elements inherent in the very conception of language-games. The integrity of natural and hypothetical elements help together to make up the idea of language-games. See Ma (2004).

${ }^{64}$ Bulmer (1968: 129). Wittgenstein says darkness is not a colour ( $R C$ III, §156).

${ }^{65} R C$ III, §130. Cf. also the hypothetical people who "have a word, say, 'leaf-colour”" (LWPP I, §220).
} 
We can stipulate the properties of "our" colours, "our" red, and "our" sepia, but alternative ways of ordering appearances are possible. Often in other traditions there is not such a clear differentiation of colour and appearance generally.

There are many places where Wittgenstein's examples of colour language games have different interpretations, depending on whether one assumes "same colour" to refer to one (unique) shade of colour or all shades coming under a general term such as "sepia." ${ }^{66}$ In some cases Wittgenstein goes along with the definition of "same colour" in terms of hue, saturation, and light/brightness: ${ }^{67}$

Just as two suits have the same [shade of] colour, if they match one another in brightness, saturation, etc.

That is to say: same Munsell code (or similar three-dimensional colour system) entails being the same colour. But more often he stresses that: 68

The meaning of "same colour" depends on the criterion we adopt for sameness of colour.

We have not one but several related concepts of the sameness of colours.

The ambiguity of "same colour" is at the bottom of the multi-interpretability of texts such as: ${ }^{69}$

Seeing what is in common. Suppose I show someone various multicoloured pictures, and say: "The colour you see in all these is called 'yellow ochre' ['Ocker']". - This is an explanation that another person will come to understand by looking for, and seeing, what is common to the pictures. Then he can look at, can point to, the common feature.

Are we to assume that what is common to the pictures is that they all contain an "identical" patch of yellow ochre? Or are we to assume that many patches are all slightly different, but seem to belong together (relative to the other colours in the pictures). ${ }^{70}$ In the first case the name taught would be the name of one shade, perhaps

\footnotetext{
${ }^{66} \mathrm{Cf}$. "But here questions could arise like "do you call just this shade of colour red, or also other similar shades?" ( $P G, \S 24)$.

${ }^{67} P R, \S 61$.

${ }^{68} P G: 353$ and $R C$ III, $\$ 251$. Cf. $R C$ I, $\S \S 17,56$.

${ }^{69} \mathrm{PI}, \S 72$; cf. $B B B: 130-135$.

${ }^{70}$ Unless a detailed conceptual ordering of the domain of "colour" (and possible overlap or fusion with other domains) is already assumed, the instruction "look at what they have in
} 
the shade of the standardised colour "yellow-ochre" artists use. In the second case there remains uncertainty on how to draw the boundary between the space of yellowochre in between yellow, brown, and red. In the case of indistinguishable samples of yellow-ochre, the learner would not yet know anything about the extension of different shades of yellow-ochre. In the second case a dictionary-type description might serve the purpose as well.

In the next passage from $\S 72$ cited, "the same colour" is ambiguous again between all figures having indistinguishable appearance or having a variety of appearances of yellow-ochre:

Compare with this a case in which I show him figures of different shapes, all painted the same colour, and say: "What these have in common is called 'yellow ochre'."

How does the "he" know that the "I" is pointing to "the same colour" (instead of some special class of shapes or samples)? The word "colour" is not mentioned in the utterance providing the ostensive definition of yellow ochre.

The English text makes the label into an explicit colour word, viz. yellow ochre, but that is not the case in German. In German the word Ocker also refers to the pigment ochre. Perhaps the figures of different shapes have all been painted with the same pigment What if we ask about the colour as defined by the appearance of this pigment $?^{71}$ Dictionaries of European languages differ in what they tell us about the colour of the pigment. ${ }^{72}$ The possible colours of the "earthy" pigment would be a part of colour space bounded or partly overlapping with red, yellow, and brown. The pigment as sold today has been purified, standardized (but different manufacturers may use a different standard). In other forms of life an atypical sample of yellow-ochre may

common" is not determinate.

${ }^{71}$ In $R C$ I, $\S 59$ and III, $\$ 265$, Wittgenstein makes the distinction between painting a spot with the pigment ochre and the colour that may appear different in different surroundings.

${ }^{72}$ Dictionaries of modern Western languages vary in what they say about the colour ochre (Ocker?) and the colour of the pigment ochre/Ocker; in German: yellow-brown; in English: usually red or yellow, especially yellow ochre; also: varying in colour from light yellow to brown to red. This vagueness or variableness is the common situation for traditional ways of making dyes and pigments. 
be the most salient, say, in being the appearance of the robes of the ruling class (dyed with the same stuff of variable appearance).$^{73}$

\section{Family resemblance across traditions: game and Spiel}

In this section our comparison of English game and German Spiel aims to introduce the idea of family resemblance across traditions. Section 66 of the Philosophical Investigations reads:

Betrachte z.B. einmal die Vorgänge die wir «Spiele» nennen. Ich meine: Brettspiele, Kartenspiele, Ballspiele, Kampfspiele, u. s. w. (German original).

Consider for example the proceedings that we call "games". I mean board-games, card-games, ball-games, Olympic games, and so on. (English translation of Anscombe; first three editions of $P I$ ).

Consider, for example, the activities that we call "games". I mean boardgames, card-games, ball-games, athletic games, and so on. (English translation of Hacker and Schulte; fourth edition of $P I$ ).

Kampfspiele originally referred to medieval knightly sports (tournaments). Today it is often translated as contests or competitions. There is no easy way of rendering Kampfspiele in English using the word game(s). Anscombe substituted Olympic games to which Wittgenstein may have agreed. Hacker and Schulte decided to translate it as athletic games.

Although commentators know Wittgenstein wrote the Philosophical Investigations in German and recent editions in English give the German text on opposite pages, commentators rarely address the differences between Spiele and games. Even when they do so, they do so only in passing; and usually conclude: "This does not significantly affect Wittgenstein's point." 74

German dictionaries have long entries for Spiel, das Spielen, and spielen, which roughly correspond to game or play (noun), playing, and to play respectively. A literal translation in German of "playing a game" would be ein Spiel spielen. The major meaning(s) of Spiel include: 75

\footnotetext{
${ }^{73}$ For the "robes of the ruling class" cf. $B B B: 134$.

${ }^{74}$ Baker and Hacker (2005: 153).

${ }^{75}$ Following Wahrig's dictionary, excluding many idiomatic meanings, such as the play of
} 
- purposeless amusement, entertainment, diversion, pastime;

- as above, but according to particular rules;

- game in the sense of match: competing against another, in particular sports;

- gambling;

- performance (theatre play, playing an instrument).

Dictionary entries for game are not much different, but not the same, because sometimes Spiel should be translated as play (and not game); for example a Schauspiel is a play or drama. Wittgenstein does not seem to include performances in his intended family of games/Spiele; from the perspective of the German language this is not self-evident, whereas in English theatre plays are obviously not games. ${ }^{76}$ On the other hand, the meaning cluster which Webster's dictionary refers to as COURSE, PLAN, TACTIC and lists as the second meaning of game, is not so pronounced in the meaning of Spiel. For example, the expression "waiting game" is translated into German without using the word Spiel. Hence, the difference between game and Spiel may cause different questions to be raised concerning Wittgenstein's text. Is the child in $\S 66$ playing a game or playing about?77 This question does not arise in this form in German. Playing about is not always playing a game. But spielen is always ein Spiel spielen.

Many commentators assume that game and Spiel are both rule-governed. 78 However, in the colloquial sense of rule-governed, a Spiel is not necessarily rulegoverned, as the above list of meanings of Spiel from Wahrig's dictionary shows, although a game is often understood to be governed by rules. Making up the rules as we go along is more closely connected to playing than with playing a game. ${ }^{79}$ Because

eyes or hands, or the technical use as in "there is too much play in the steering"; as well as many figurative expressions: play of colours, vagaries of fortune, freak of nature, play on words. In German these are all examples of ein Spiel.

${ }^{76}$ Wittgenstein does include gambling (Würfelspiel), although it may not always be a good example of game (marginal note to $P I, \S 69 ; P G, \S 75$ ). Perhaps it might be suggested that Wittgenstein used the words game and Spiel as synonyms, but that would be a remnant of the ideal language paradigm.

77 "A child throws his ball at the wall and catches it again" $(P I, \S 66)$.

${ }^{78}$ For example, Glock (1996: 121) and Baker \& Hacker (1985: 214).

${ }^{79} \mathrm{Cf}$. PI, §83, where the verb spielen occurs: “And is there not also the case where we play [spielen] and make up the rules as we go along? And even where we alter them-as we go 
of the differences between Spiele and games, the interpretation of Wittgenstein's use of the neologism Sprachspiel(e) or language game(s) takes on different shades or nuances of meaning.

We conclude that one should read Wittgenstein's text in terms of Spiele, not in terms of games. The verbs to play and spielen have a closer family resemblance than the nouns game and Spiel. When one considers other languages, one will find different family resemblances. However, this is not the case if a concept has a stipulated meaning in a global context, for example "Olympic games." Family resemblance across traditions may follow from a shared origin, or, most generally speaking, is grounded in the similarity of human practices. Extension of FR-concepts across traditions is possible because of the mutual recognition of human practices (forms of life). ${ }^{80}$

Although admittedly merely a didactic example, because the histories of the concepts game and Spiel are not unrelated, it shows how extension of FR-concepts works in principle. The English concept game can be extended to include (a large part of) the German Spiel and the latter can be extended to include most or all games.

\section{What about playing another game?}

In section 72 of the Philosophical Investigations Wittgenstein further writes:

And compare this case: I show him samples of different shades of blue, and say: "The colour that is common to all these is what I call 'blue'."

As Wittgenstein suggests in the Brown Book, somebody from another tradition may not understand, because, for example, this person might distinguish light and dark blue as separate "basic" colours:81

along."

${ }^{80}$ To elucidate the latter would require a length discussion of $P I, \S 206$, concerning "shared human behaviour [gemeinsame menschliche Handlungsweise; earlier English translation: 'common behaviour of mankind']" and Wittgenstein 2009b, §22 (concerning Einstellung zur Seele), henceforth referred to as $P P F$.

${ }^{81} B B B$ : 134-135. A concrete example might be Russian. It has been argued that it has two "basic colour terms" for dark blue sinii (синий) and light blue goluboj (голубой) respectively. Wittgenstein may have known of this. (In the 1930s he studied Russian and visited the USSR.) However, what is more relevant may be that dark blue and light blue are the colors of Oxford and Cambridge respectively. In the German text of Das Braune Buch light and dark red are 
Now what should we answer to the question "What do light blue and dark blue have in common?" At first sight the answer seems obvious: "They are both shades of blue". But this is really a tautology. So let us ask "What do these colours I am pointing to have in common?" (Suppose one is light blue, the other dark blue.) The answer to this really ought to be "I don't know what game you are playing". And it depends upon this game whether I should say they had anything in common, and what I should say they had in common. ...

We could also easily imagine a language (and that means again a culture) in which there existed no common expression for light blue and dark blue, in which the former, say, was called "Cambridge", the latter "Oxford". If you ask a man of this tribe what Cambridge and Oxford have in common, he'd be inclined to say "Nothing". ...

To say that we use the word "blue" to mean "what all these shades of colour have in common" by itself says nothing more than that we use the word "blue" in all these cases.

One might still insist: "But don't you see the similarities?" Of course; but what about somebody who says: Yes, I know what is common. It is all qing 青, a Chinese word, sometimes translated as blue, sometimes as green. ${ }^{82}$ At various places Wittgenstein reminds us that all his remarks about colour refer to "our" colours. ${ }^{83}$

There is, after all, no commonly accepted criterion for what is a colour, unless it is one of our colours.

Can't we imagine people who do not have our colour concepts but who have concepts which are related to ours in such a way that we would also call them "colour concepts."

used as an example instead of light and dark blue. It is not clear why Wittgenstein at some point crossed out (Hell/Dunkel)blau and substituted (Hell/Dunkel)rot (Wittgenstein 2000, MS 115: 237, 239). The two forms of phytochrome (a plant pigment) can be associated with light red and dark red. In English the pair red - far red is more common. In German the pair Hellrot - Dunkelrot is more common. The second half of the citation is only in the English version of the Brown Book.

${ }^{82}$ Dictionary definitions of qing vary; an example: "nature's colour (blue, green, greenishblack)."

${ }^{83}$ Citing $R C$ I, $\S 14$ (or III, §42), §I.66 (or III, §154) and III, §127 respectively. See, in addition LWPP I, §§220, 930; PPF, §345; RPP I, §§608, 622; Z, §331. 
There is no indication as to what we should regard as adequate analogies to our colours.

Confronted with people who don't seem to have "our" colours, we may roughly distinguish the following situations:

1. If their visual system is different, there is nothing we can say. ${ }^{84}$

2. There is sufficient similarity to justify suggesting an extension of our colour category to include their concepts. This may also happen within one tradition. For example, Wittgenstein claiming that there are four primaries; others claiming that there are three primaries.

3. The other people have nothing resembling our colour concepts. However, they have appearance concepts, which are "accessible" by extension of some of our FR-concepts or the interpreter can construct a "new" hybrid concept, which is similar to the alien concept(s).

Colour is a prominent aspect of appearance for an increasing number of people. As a consequence of the regimentation of modern languages to (alleged) results of scientific research, research in many disciplines takes for granted that such modern categories as "colour" are human universals, also for times long ago. For example, in a study on "colour terms in Shang oracle bone inscriptions," the author argues that animals of various colours were offered to sacrifice, and that over time, in selecting animals for sacrifice, the colour of ritual animals had gradually become important. ${ }^{85}$ Wang's exceptionally detailed study never raises any questions concerning the assumption that the subject of study is colour terms in Shang oracle-bone inscriptions and he even modifies translations to fit his discourse. For example a classical translation of the following passage from the Liji is:" "The ruler ordered the oxen to be brought before him, and inspected them; he chose them by their hair [mao 毛], ..."

\footnotetext{
${ }^{84} \mathrm{Cf}$. $R C$ III, $\S \S 42,127$. This also applies to animals who allegedly see "colours" different from colours.

${ }^{85}$ See Wang (2007). The (Chinese) Shang dynasty is dated 1600-1046 BCE.

${ }^{86}$ The citation is from Book 24 ("Meaning of sacrifices") of the Liji (Book of Rites), which is a diverse collection of Chinese texts of uncertain origin and date, perhaps written down about two millennia ago.
} 
Wang's translation of the relevant passages is: "The choice is made regarding the colour of the animal [mao 毛], ...."87 The Chinese character mao never means colour.

This is a clear case of "cleansing the data" in order to support one's interpretation. If one reads Wang's descriptions of the use and meaning of the relevant Chinese characters, it is obvious that the oracle bone discourse does not so much share a family resemblance with modern colour discourse. Rather there is family resemblance with the variety of terms used in "cattle-fur-appearance-discourse" (henceforth: CFAD), often found in traditions where horses, cows, or other large mammals play an important role. Already in 1880 Magnus noted that Xhosa people in those days distinguished between twenty-six "cattle colours" and found it hilarious that Europeans used different names for blue and green. ${ }^{88}$ One may speculate that CFAD-idiom would consist of hybrid concepts "integrating" appearance features such as the smoothness of the animal fur, its dullness/brightness, its chromatic hue, its being variegated or not, showing patterns or not, its appearance at dawn, and similar appearance features, as well as related evaluative features. ${ }^{89}$

Such CFAD-terms don't qualify as colour words. ${ }^{90}$ In modern European languages colour is a subclass of appearance. Passing over the complexities of "appearance" across traditions, ${ }^{91}$ we may say that CFAD-terms come directly under the category of appearance, whereas nothing corresponds to "our" colour in CFAD-grammar. Like all FR-concepts, CFAD-terms were extended as time moved on; for example by extending the use of CFAD terms for animals to the appearance of soils, garments, clouds and eventually, after contact with the "centre," abstract colour grammar.

\footnotetext{
${ }^{87}$ Wang (2007: 334, emphasis added).

${ }^{88}$ Magnus (1880). Strictly speaking: no words for the German words grün and blau. Even in today's English one can still find colour-pattern idiom such as colour-sided (or lineback) and finching, indicating a particular colour pattern on domestic animals.

${ }^{89}$ It is apparent from Wang's discussion that some CFAD-terms, at the time, might be restricted to one type of animal such as bulls or horses.

${ }^{90}$ The construction and structuring of the domain of colour, an intuitive self-evident category today, is the result of a convoluted history of what is now called colour science.

${ }^{91} \mathrm{Cf}$. the large difference between western appearance (the sensuous) and the Buddhist category of rüpam (in Sanskrit), se (in Chinese), or shiki (in Japanese). See for discussion Ma (2008: 182-185).
} 


\section{Concluding remarks}

We have argued that all the general concepts function as FR-concepts, including concepts introduced by ostension, such as colour(s). It is possible to define a concept in terms of necessary and sufficient conditions, but this stipulation will contain FRconcepts. Hence, the stipulated concept is a FR-concept at one remove.

In particular we have argued that the concepts of colour and of each of the specific colours are FR-concepts, because similarities crop up and disappear concerning an open-ended range of colour or appearance features. A simple three-dimensional notion of colour cannot deal with the appearance of metallic lustre or polished wood (such as mahogany). ${ }^{92}$

Wittgenstein often remarks that what he (and we) can say about the phenomenology of colour concerns our colour grammar. No predetermined answer can be given as to what to say about people who don't use "our" colour concepts, but have favoured different ways of ordering appearances. The alternative orderings of these people may show a lesser or greater similarity to our colour conceptual schemes and they may (from our perspective) not have a concept of colour but concepts involving what we might call any of the following: brightness, darkness, lustre, shiny, glow, glittering, ripeness, wetness, fashionable, sheen, lurid (and more). There is no necessity for a form of life to use what we call colour concepts.

We want to make a final remark concerning the ambiguity of the word "our" in expressions such as "our colours." There are at least two respects in which Wittgenstein's phenomenological or conceptual analysis may be (somewhat) biased in favouring a particular colour theory. On many occasions he emphasises:

1. There are four primaries (red, green, yellow, blue). ${ }^{93}$

2. There is a pure green (red, yellow, blue) in a way that there isn't a pure violet (orange, brown, pink). ${ }^{94}$

\footnotetext{
${ }^{92}$ Sometimes lustre or shininess (of metals, silk, graphite) can be described as being brighter than white under the same lighting conditions. Lustre tends to obliterate surface texture and seems to hover above the surface. Glitter is sometimes described as luster plus movement.

${ }^{93} R C$ III, §134: "there are four (or, with white and black, six) pure colours."

${ }^{94} R P P \mathrm{I}, \S 47 ; R C$ III, §133.
} 
These two "psychological" characteristics of "our" colours, together with the idea of opponent colours (to which Wittgenstein also seems sympathetic), forms the backbone of Ewald Hering's (scientific) colour theory. ${ }^{95}$

It is important to add that for Wittgenstein "pure green," etc. is not an objective feature of the world, which it might be when defined in terms of a particular wavelength in the spectrum. ${ }^{96}$

There can also be a disagreement about what colour an object is. To one person it appears as a somewhat yellowish red, to another as a pure red.

Wittgenstein repeats several times that brown is not a primary, not a pure colour. ${ }^{97}$ Probably nobody would suggest this. In a way brown (and for similar reasons: pink) are not independent hues. The hue of brown is yellow. If a brown colour patch is completely decontextualised, it will look yellow. Some colours can only be seen if surrounded by particular (colour) surroundings (as Wittgenstein also notes). Orange and violet would be better candidates to discuss. There is no clear brown, ${ }^{98}$ but there is a clear orange. Violet and orange occur in the spectrum and have been assigned wavelengths corresponding to pure orange and pure violet. 99

Wittgenstein is aware that not everybody might agree with him concerning the (relevance of) the four primaries: ${ }^{100}$

If someone had called this difference between green and orange to Runge's attention, perhaps he would have given up the idea that there are only three primary colours.

Couldn't there be a painter, for example, who had no concept

${ }^{95}$ Hering's basic ideas might be traced back to Goethe and are today represented in colour science by the Scandinavian "Natural Colour System," one of the many models of ordering colour space.

${ }^{96}$ LWPP II: 24.

${ }^{97}$ LWPP I, §213; RC III, §§60, 65.

${ }^{98} R C$ III, $\S 60$.

${ }^{99}$ Dictionaries may accept orange and violet as practical primaries in that they allow to define yellow as the colour between red and orange and blue as between green and violet. This is the influence of the colours in the spectrum. Wittgenstein had no comments on the spectrum, presumably because he considered it physics.

${ }^{100} R C$ III, $\S \S 28,113$; cf. $R C$ III, $\S 26$. Wittgenstein reserves the possibility of three primaries to colour-blind people ( $R C$ III, $\S 128)$. 
whatsoever of 'four pure colours' and who even found it ridiculous to talk about such a thing?

But Wittgenstein doesn't doubt that his conceptual-phenomenological analysis is correct. There are four primary colours. However, for most applications of colour three primaries are used. This could be red, green, and blue at equal distance (for mixing lights); or, for mixing pigments: magenta, yellow and cyan. ${ }^{101}$

Other phenomenological "facts" mentioned by Wittgenstein are mirrored by the Munsell solid and other models of colour space. That is to say, here phenomenology and physics seem to coincide. ${ }^{102}$ For example: ${ }^{103}$

But pure yellow too is lighter than pure, saturated red, or blue.

This corresponds to yellow being above and red being below the equator of the Munsell colour solid. Wittgenstein favours a colour circle with four primaries and speaks, as Hering and Goethe did, of red/green and yellow/blue being opposite one another in the colour circle, but as he himself points out: ${ }^{104}$

Blue and yellow, as well as red and green, seem to me to be opposites-but perhaps that is simply because I am used to seeing them at opposite points on the colour circle.

The equal distances of the primary colours are arbitrary. Indeed, the transitions would perhaps make a more uniform impression on us, if, e.g., the pure blue were nearer to the pure green than to the pure red.

The last remark corresponds with the "scientific" observation that, in terms of just noticeable differences, red is opposite cyan in the colour circle, not opposite green.

We conclude that Wittgenstein's many remarks on colour(s) should be read as applicable to "our" (European) colours (as he often stresses), whereas the basis or outcome of conceptual analysis of "our colours" may not always be as self-evident as

${ }^{101}$ In order to improve LCD TV and computer screens five primaries (red, yellow, magenta, cyan, ultramarine) are used to reproduce the original colors with high fidelity; i.e. obtain an extended colour gamut and more increased white brightness. But this is technology, not conceptual analysis.

${ }^{102} R C$ II, §16: "Phenomenological analysis (as e.g. Goethe would have it) is analysis of concepts and can neither agree with nor contradict physics."

${ }^{103} R C$ III, §4; cf. $§ 161$.

${ }^{104} R C$ III, $\$ 26$ and $R P P$ I, $\$ 623$. 
Wittgenstein seems to assume, when stipulating, for example, that there are four (or six) pure primary colours. Of course, these provisos may be irrelevant to a general theme for which colour(s) serve as samples/examples, including our view that concepts introduced by ostensive definitions are FR-concepts.

\section{References}

Baker, G.P., and P.M.S. Hacker. 1980. Wittgenstein: Understanding and Meaning. Part I: Essays. Vol. 1 of An Analytical Commentary on Wittgenstein's Philosophical Investigations. Oxford: Blackwell.

Baker, G.P., and P.M.S. Hacker. 1985. Wittgenstein: Rules, Grammar and Necessity. Vol. 2 of an Analytical Commentary on the Philosophical Investigations. Oxford: Blackwell.

Baker, G.P., and P.M.S. Hacker. 2005. Wittgenstein: Understanding and Meaning. Part I: Essays. Vol. 1 of An Analytical Commentary on Wittgenstein's Philosophical Investigations. Oxford: Blackwell.

Bambrough, R. 1960/61. Universals and family resemblances. Proceedings of the Aristotelian Society, New Series 61:207-222.

Bulmer, R.H.N. 1968. "Karam colour categories." Kivung 1:120-133.

Ereshefsky, M. 2010. "Microbiology and the species problem." Biology \& Philosophy 25:553568.

Forster, M. 2010. "Wittgenstein on family resemblance concepts." In Wittgenstein's Philosophical Investigations: A critical guide, edited by A. Ahmed. Cambridge: Cambridge University Press.

Frege, G. 1892. "Über Sinn und Bedeutung." Zeitschrift für Philosophie und philosophische Kritik 100:25-50.

Gert, H.J. 1995. "Family resemblance and criteria." Synthese 105:177-190.

Glock, H.-J. 1996. A Wittgenstein Dictionary. Oxford: Blackwell.

Hopkins, E.W. 1883. "Words for Color in the Rig Veda." American Journal of Philology 4:166-191.

Ma, L. 2004. Would Wittgenstein approve a distinction between invented and natural language-games? In Papers from the Twenty-Seventh International Wittgenstein Symposium, edited by J. C. Marek and M. E. Reicher, pp. 212-214.

Ma, L. 2008. Heidegger on East-West Dialogue: Anticipating the Event. New York: Routledge.

Magnus, H. 1880. Untersuchungen über den Farbensinn der Naturvölker. Jena: Fischer. 
Merleau-Ponty, M. 1973. The Prose of the World. Evanston: Northwestern University Press.

Pelczar, M. 2000. "Wittgensteinian semantics." Nous 34 (4):483-516.

Quine, W.V.O. 1969. Ontological Relativity and Other Essays. New York: Columbia University Press.

Quine, W.V.O. 1974. The Roots of Reference. LaSalle: Open Court.

Quine, W.V.O. 1996. "Progress on two fronts." The Journal of Philosophy 93 (4):159-163.

Rosch, E., and C.B. Mervis. 1975. "Family Resemblances: Studies in the internal structure of categories." Cognitive Psychology 7 (4):573-605.

Rowe, M.W. 1992. "The definition of 'game'." Philosophy 67 (262):467-479.

Sluga, H. 2006. "Family resemblance." Grazer Philosophische Studien 71:1-21.

van Brakel, J. van, and L. Ma. 2015. Possibility of comparative philosophy II: Extension of family resemblance concepts as a necessary condition of interpretation across traditions. Dao: A Journal of Comparative Philosophy: forthcoming.

von Savigny, E. 1994. Wittgensteins Philosophische Untersuchungen: Ein Kommentar für Leser. Band I: Abschnitte 1 bis 315. Frankfurt a/M: Klostermann.

Wang, T. 2007. "Shang ritual animals: colour and meaning (part 1)." Bulletin of the School of Oriental and African Studies 70 (2):305-372.

Wittgenstein, L. 1969. The Blue and Brown Books: Preliminary studies for the Philosophical Investigations. Oxford: Blackwell.

Wittgenstein, L. 1974. Philosophical Grammar, edited by R. Rhees. Oxford: Blackwell.

Wittgenstein, L. 1975. On Certainty, edited by G.E.M. Anscombe and G.H.v. Wright. Oxford: Blackwell.

Wittgenstein, L. 1977. Remarks on Colour, edited by G.E.M. Anscombe. Berkeley: University of California Press.

Wittgenstein, L. 1978. Remarks on the Foundations of Mathematics, edited by G.H.v. Wright, R. Rhees and G.E.M. Anscombe. Oxford: Blackwell.

Wittgenstein, L. 1979. Notebooks 1914-1916, edited by G.E.M. Anscombe and G.H.v. Wright. Oxford: Blackwell.

Wittgenstein, L. 1980. Remarks on the Philosophy of Psychology, edited by G.E.M. Anscombe and G.H.v. Wright. Oxford: Blackwell.

Wittgenstein, L. 1981. Zettel, edited by G.E.M. Anscombe and G.H.v. Wright. Oxford: Blackwell.

Wittgenstein, L. 1990. Last Writings on the Philosophy of Psychology. Vol. I. Oxford: Blackwell. 
Wittgenstein, L. 1992. Last Writings on the Philosophy of Psychology. Vol. II. Oxford: Blackwell.

Wittgenstein, L. 1993. "Remarks on Frazer's Golden Bough." In Philosophical Occasions 1912-1951, edited by J.C. Klagge and A. Nordmann, 118-155. Indianapolis: Hackett.

Wittgenstein, L. 1998. Philosophical Remarks, edited by R. Rhees. Oxford: Blackwell.

Wittgenstein, L. 2000. Wittgenstein's Nachlass: Text and facsimile version. The Bergen Electronic Edition. Bergen and Oxford: Wittgenstein Archives at the University of Bergen and Oxford University Press.

Wittgenstein, L. 2009a. Philosophical Investigations. Oxford: Blackwell. Fourth edition, translated by G. E. M. Anscombe, P. M. S. Hacker and J. Schulte. Oxford: WileyBlackwell.

Wittgenstein, L. 2009b. Philosophy of Psychology - A Fragment. Translated by G.E.M. Anscombe, P.M.S. Hacker and J. Schulte. 4th ed. Oxford: Wiley-Blackwell (2009b). Formerly part II of $P I$.

Broekstraat 82/101

3001 Heverlee (Leuven)

Belgium

lin.ma.2007@gmail.com

Jaap.vanBrakel@hiw.kuleuven.be

We conclude that conventional concepts can also be considered to be FR concepts in the final analysis, because the (sub-) concepts used to define them are FR concepts (or via other sub- sub- concepts, can be revealed as eventually dependent on certain FR concepts). 